\title{
Numerical Simulation of Aerogasdynamics Pro- cesses in A Longwall Panel for Estimation of Spontaneous Combustion Hazards
}

\author{
Sergey Meshkov ${ }^{1}$, and Andrey Sidorenko ${ }^{2 *}$ \\ ${ }^{1}$ JSC SUEK Kuzbass, 652507, 1, Vasilyev St., Leninsk-Kuznetsky, Russia \\ ${ }^{2}$ Saint Petersburg Mining University, 199106, 21 line, 2, Saint Petersburg
}

\begin{abstract}
The relevance of a solution of the problem of endogenous fire safety in seams liable to self-ignition is shown. The possibilities of numerical methods of researches of gasdynamic processes are considered. The analysis of methodical approaches with the purpose to create models and carry out numerical researches of aerogasdynamic processes in longwall panels of gas mines is made. Parameters of the gob for longwall mining are considered. The significant influence of geological and mining conditions of conducting mining operations on distribution of air streams on longwall panels and effective management of gas emission is shown. The aerogasdynamic model of longwall panels for further research of influence of parameters of ventilation and properties of gob is presented. The results of numerical researches including distribution of air streams, fields of concentration of methane and oxygen at application of various schemes of airing for conditions of perspective mines of the Pechora basin and Kuzbass are given. Recommendations for increase of efficiency of the coal seams mining liable to selfignition are made. The directions of further researches are defined.
\end{abstract}

\section{Introduction}

The endogenous fires in coal mines still represent a danger being the second most important after explosions of methane for all leading coal-mining countries as despite the low frequency of emergence result in significant economic damages and extreme danger to life of miners $[1,4,15,17]$. Modern researchers even more often point to the endogenous fire, as to the most probable cause of explosion of metane-air mix at gob areas of the seams liable to selfignition. The main place of emergence of the endogenous fires are the gob areas - both the operating mining panels and those which have been mined earlier $[8,13]$. The complexity of studying the process of self-ignition in mine conditions predetermines wide use of laboratory researches $[1,11]$ and computer modeling $[2,3]$.The existing modern program complexes, for example, of Ansys Fluent, Ansys CFX, FlowVision and others, allow to model gasdynamic processes in systems of varying complexity that causes expediency of their use for studying aerogasdynamic processes on longwall panels of the gas mines in the course of

\footnotetext{
*Corresponding author: sidorenkoaa@mail.ru
} 
mining coal seams liable to self-ignition. The main directions of aerogasdynamic researches with the use of program complexes are connected with studying the distribution of air streams and methane [16] and also with studying the distribution of oxygen on a longwall panel when using various schemes of ventilation with identification of dangerous zones, with the subsequent processing or change of parameters of ventilation and draining of methane [7,9]. The complexity of ensuring adequacy of the models to real conditions used by researchers is connected, first of all, with insufficient study of a gob area and influences of their characteristics (collapse zone height, porosity, permeability, etc.) on aerogasdynamic processes [10]. In this connection studying of influence of the specified characteristics of a gob when using various ways of management of gas in entries of longwall panels on formation of the zones dangerous on self-ignition of coal is of considerable scientific and practical interest [14].

\section{Materials and methods}

The three-dimensional aerogasdynamic model of the longwall panel including entries, longwall and gob has been developed for carrying out researches. Modeling was carried out in scale 1:1. The gob was modelled as a porous body whose parameters were defined with the methodical approach stated in earlier published of other researchers $[2,3,5]$. The need of allocation for the gob areas of zones with various permeability was emphasized by many researchers $[2,6]$, however, the impossibility of exact determination of permeability in mine conditions has caused the need of searching for other solutions. In the used model the extinguished developments, the part of the gob which is directly adjoining a longwall, the top and lower parts of the gob on removal from a longwall equal to 6 steps of collapse of the main roof and other gob have various permeability. Now the permeability of the gob when carrying out numerical researches is determined either on the basis of numerical researches with the use of methods of mechanics of the discrete medium which allow to define distribution of rock pressure in the gob, or with use of empirical formulas. So, for example, it is proposed to determine permeability by the formula [2]:

$$
K=\frac{K_{0}}{0.241}\left(\frac{n^{3}}{(1-n)^{2}}\right),
$$

$K_{0}$ - basic permeability, at the maximum porosity of the broken-down rocks; $n$ - porosity.

Methane emission on the longwall panel was set: in the gob - from under- and above-mining seams, from the surface of a coal face and from the rotted coal. Parameters of gas emission, methane drainage and ventilation at the initial stage were set according to the actual mine data for further comparison of results of modeling and correction of model. Carrying out numerical researches of aerogasdynamic processes on longwall panel with use of the program ANSYS complex included the following consecutive actions: a task of geometry of entries and the gob taking into account specific geological and mining conditions, installation of parameters of a spatial grid and splitting model into elements, determination of physical parameters of model and boundary conditions (input-output parameters), carrying out the numerical solution, processing and visualization of results, the analysis of results.

\section{Results and discussion}

As a result of the conducted numerical researches the assessment of efficiency of various schemes of ventilation and gas drainage was made applied in Kuzbass in the field of ensuring effective gas management and endogenous fire safety at longwall mining. Visualization of results of researches has allowed to reveal the most dangerous zones, to estimate influence 
various technological (ventilation schemes and gas drainage and their parameters) and geological (extracting seam thickness, parameters of a gob, gas emission) factors and has provided fuller understanding of aerogasdynamic processes on a longwall panel and a gob. As a result of researches the distribution of gases within entries and the gob of longwall panel for various geological and mining conditions is established. As an example of the received results figure 1 shows methane in the working area (in entries, longwall and gob) in the plane passing parallel to bedding at the height of $2.5 \mathrm{~m}$ from the coal floor is presented, and fields of concentration of oxygen are given in the figure 2 in the same plane.

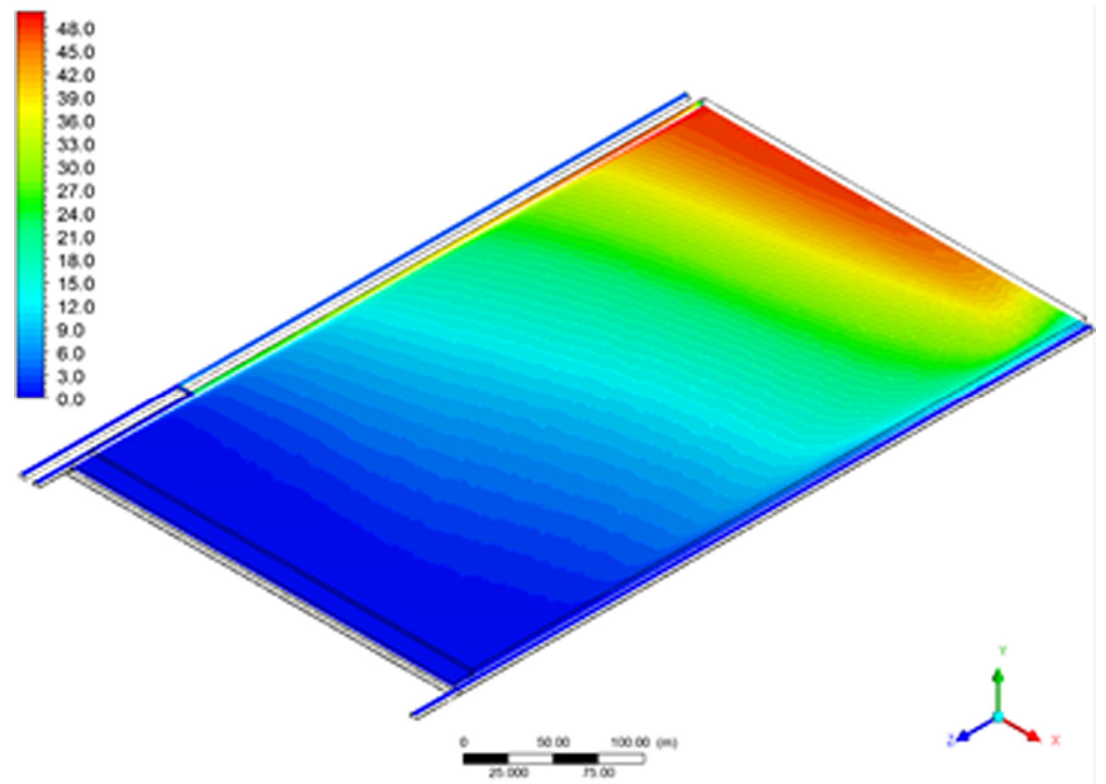

Fig. 1. Concentration of methane in the longwall panel, \%.

By researches it is established that concentration of oxygen in the gob remains within firedangerous values (10\%) on considerable removal (up to $400 \mathrm{~m}$ and more) from the longwall. The intensity of ventilation of the gob and possibility of formation of dangerous zones substantially depend on permeability of the broken-down rock and parameters of the applied way of gas management on the longwall panel. Researches into influence of parameters of the combined schemes of ventilation providing maintenance of conveyor entry behind a longwall on the site to the next air connection have shown that significant effect in a longwall the size of residual cross section of the airtaking-away development supported behind a longwall and also timeliness (lag from a longwall) and quality of repayment behind a longwall of the airgiving development for minimization of leak of air in a deadlock part of entry on the headgate (at the descending order of mining). 


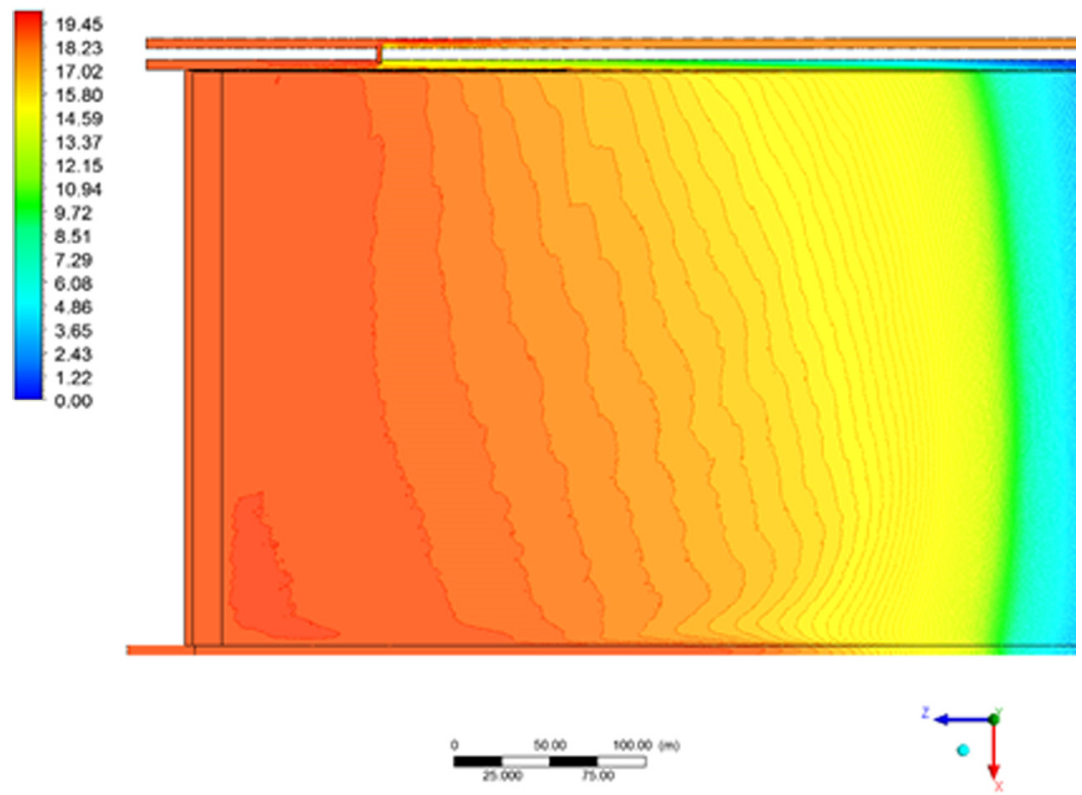

Fig. 2. Oxygen concentration in the working area, $\%$.

Researches have shown that the permeability of the developed spaces is one of the main characteristics defining intensity of processes of ventilation, filtration and movement of gases. The summing up of research results of various authors [16] shows that the minimum permeability of the developed spaces as a result of application of such approaches can be found in the range from $3 \times 10^{3}$ to $2.03 \times 10^{9} \mathrm{mD}$, and maximum from $1.25 \times 10^{5}$ to $2.03 \mathrm{x}$ $10^{10} \mathrm{mD}$, and the values of permeability for conditions of one and the same mine applied by different authors may vary up to 1000 times. At the same time the distinction between maximum and minimum permeability, by results of researches of various authors, is from 10 to 58 times. Such considerable range of the used values of permeability may mean high variability of geological conditions at gob of longwall panels which length reaches $4-5 \mathrm{~km}$ and more now and also significant influence of technological parameters (length of a longwall and speed of a coal face) on processes of deformation and the collapse of rocks of a roof. The ratio of the extracting seam thickness and thickness of the immediate roof as well as the sizes of blocks of immediate and main roof have significant effect on permeability of the developed space. It should be noted the permeability of the gob decreases in the process of removal from a longwall and also with time (in connection with development of geomechanical processes). Formation of aerodynamic communication exerts considerable impact on distribution of gases on the gob and has to be considered when carrying out numerical modeling. According to the present research, it is recommended to update the characteristics of the developed space after comparison of results of numerical researches and mine observations which can be carried out on the basis of assessment of distribution of air on the longwall panel and leak of air in the gob.

\section{Conclusions}

Numerical researches of aerogasdynamic processes are one of the main methods of the researches providing the solution of a problem of distribution of air streams, concentration of methane and oxygen for the wide range of geological and mining conditions that proves 
high efficiency of the considered method for assessment of endogenous fire safety of the applied technological schemes of mining and schemes of ventilation. The fields of distribution of oxygen received as a result of numerical researches in gob areas allow to predict formations of dangerous zones and to provide decrease in endogenous fire danger of mining of the coal seams liable to self-ignition, by change of parameters of schemes of development of longwall panels, schemes of ventilation and gas drainage or carrying out preventive processing of dangerous zones.

Creation of three-dimensional aerogasdynamic models of the longwall panels which are adequately reflecting the processes happening at gob areas of longwall mining flat coal seams with roof caving requires the correct determination of key parameters of the developed spaces: porosity and permeability. As the most effective method of determination of the specified parameters the empiric-analytical method based on use of the known methodical approaches $[2,5]$ and adjustment of the received sizes taking into account the actual ratios of change of permeability in mine conditions with carrying out final control of model can be offered.

The roof-caving increment of the main roof and ratio of the extracting seam thickness and thickness of the immediate roof are one of the major factors determining the volume of ventilation loss through the gob and the sizes of intensively ventilation zones. In the conditions of intensive mining the speed of longwall operations leads to the growth of the roof-caving increment in the main roof and increase of permeability of the developed space. The carried out researches have confirmed the need of the complex solution of issues of prevention of the endogenous fires and gas management in entries of longwall panels of the gassy seam liable to self-ignition.

The direction of further researches will be connected with improvement of methodical approaches to determination of parameters of gob areas and validation of the developed theoretical methods in mines.

\section{References}

1. A. Arısoy, B.B. Beamish, E. Çetegen, Turkish J. Eng. Env. Sci., 30, 193 (2006)

2. G.S. Esterhuizen, C.O. Karacan Proceeding of the 40th U.S. Rock Mechanics Symposium. Alexandria, VA: American Rock Mechanics Association., 156-160 (2005)

3. G.S. Esterhuizen, C.O. Karacan, A methodology for determining gob permeability distribution and its application to reservoir modeling of coal mine longwalls 07 (Dover, SME 2007)

4. B. Ham, Coal2005: 6th Australasian Coal Operators' Conference, 237 (2005)

5. C.Ö. Karacan, Transport in Porous Media, 82:2, 413 (2009)

6. C. Zhang, S. Tu, L. Zhang, Q. Bai, Y. Yuan, F. Wang, Journal of Geophysics and Engineering., 13:2, 181 (2016)

7. Y. Lu, S. Shi, Q. Ye, Z. Tian, Journal of Residuals Science \& Technology (JRST)., 14:3, 373 (2017)

8. W.X. Ren, B.W. Wu, Journal of Mining \& Safety Engineering., 26:2, 198 (2009)

9. A.C. Smith, L. Yuan, Mining Engineering, 60:8, 61 (2008)

10. G. Xu, K. D. Luxbacher, S. Ragab, S. Schafrik, Tunnelling and underground space technology, 33, 1 (2013)

11. H. Wen, Xi an University of Science and Technology, 46 (2003)

12. L. Yuan, A.C. Smith, Journal of loss prevention in process industries., 25, 131 (2011) 
13. R. Qin, L. Teng, S. Yuan, L. Shi, AGH Journal of Mining and Geoengineering., 36:3, $283(2012)$

14. L. Yuan, A.C. Smith, Proceedings of the 12th., 141 (2008)

15. R.V.K. Singh Procedia Engineering., 62, 78 (2013)

16. D.M. Worrall, Modeling gas flows in longwall coal mines using Computational Fluid Dynamics, Ph.D. Thesis, (The Colorado School of Mines, 2012)

17. O.I. Kazanin, Journal of mining institute, 215, 38 (2015) 